\title{
Mathematical model for producing machine parts
}

\author{
Kamolkhon Karimov", Nodir Turakhodjaev, Azamat Akhmedov, and Shukhrat \\ Chorshanbiev \\ Tashkent State Technical University named after I.A. Karimov, Tashkent, Uzbekistan
}

\begin{abstract}
In the article, the object of research is the development of a technology for improving the operational properties of cast parts from steel 45 , obtained by the method of electroslag remelting. Based on the research results, the modes of heat treatment of the shaft-gear part in an aqueous medium water-oil, heat treatment to increase the service life of the product, and energy-saving melting technology by the method of electroslag remelting were developed. Particular attention is paid to the development and analytical implementation of the mathematical model of the developed technologies by the methods of linear algebra by drawing up the Lagrange interpolation polynomial. Functional dependencies have been obtained for determining the amount of oxygen in the melt depending on the diameter of the electrode and the aluminum content in this electrode for any diameter of the mold, the hardness of the shaft surface depending on its diameter, the oxygen content (amount) in the melt depending on the aluminum content in the electrode for different mold diameters. Based on the developed and analytically implemented mathematical models of the investigated technological process, it seems possible to simplify experimental studies. In other words, based on analytical studies, it is possible to predict the results of subsequent experiments. Based on the developed and analytically implemented mathematical models of the investigated technological process, it seems possible to simplify experimental studies. In other words, based on analytical studies, it is possible to predict the results of subsequent experiments.
\end{abstract}

\section{Introduction}

In mechanical engineering, the foundry is one of the most important areas of fundamental and applied science, determining technical progress. One of the urgent problems in mechanical engineering is the development of technologies for obtaining competitive, import-substituting, and high-quality castings from ferrous and non-ferrous alloys that meet the requirements of world standards. Especially important are the materials used for the manufacture of various parts with improved performance properties for general mechanical engineering since this branch of the economy determines technical progress in general.

It is well known that electroslag remelting is one of the types of foundry production, in

* Corresponding author: kamolxon.karimov@gmail.com 
which the metal is remelted in a bath of electrically conductive slag heated by electric current. This method of remelting improves the quality of metals and alloys. The most important stage of development was the use of iron and its alloys. Iron-based alloys are still the main structural material.

In this regard, the development of innovative technologies for obtaining high-quality castings from ferrous and non-ferrous alloys, the development of technologies for the creation of high-quality, durable competitive, and import-substituting products that meet modern requirements are currently relevant for machine-building production. In this direction, research centers in many developed countries, including the USA, England, Germany, Japan, China, and Russia, pay special attention to improving the operational properties of cast products from various grades of steel, including the development of technology for melting steel 45 in electric furnaces.

Here are several studies in this direction. Scientists of England G. Bessemer and S. Thomas, researchers of France P. Martin have developed new designs and methods of steel production. The Russian scientist V. Chernov developed the degree of dependence of the strength of steel with its structure and a graph of changes in the internal structure of steel depending on heat transfer and heat treatment. Changes in the structure during welding and heat treatment of steel were developed by N.N. Benardos, N.G. Slavyanov, R. Mel, E. Bein, G. Hannemann, F. Wefer, and G. Esser [1-6].

Scientists of the CIS countries A.A. Bochvar, N.A. Minkevich, S.S., Steinberg, N.Ya. Selyakov, N.T. Gudtsov, G.V. Kurdyumov, A.P. Gulyaev, A.M. Butlerov, S.V. Lebedev, P.A. Rebinder, SP Korolev, and AT Tumanov have developed a heat treatment technology and modes for increasing the wear resistance of steels [4]. Researchers of Uzbekistan A.A. Mukhammedov, N.D. Turakhodzhaev, F.R. Norkhudzhaev, Sh.A. Karimov, and D.M. Berdiev have developed thermal and thermal cycling modes to increase strength and wear resistance [11-15].

Along with these achievements, there are many unresolved problems. In particular, no studies have been carried out to create soil for increasing the wear resistance of steels in the furnace itself during the melting process, and effective technologies have not been developed to improve the operational properties of parts obtained from the alloy grade 45 steel, the production of which in electroslag furnaces is considered resource-saving. In this regard, carrying out theoretical and practical studies to improve the strength and wear resistance of machine-building parts made of steel 45 in electroslag furnaces is urgent.

Based on the above, the research objectives are the development of technology for improving the operational properties of cast parts made of steel 45 , obtained by electroslag remelting, heat treatment to increase the service life of the product, and energy-saving melting technology by electroslag remelting, development and analytical implementation of a mathematical model [16-20].

\section{Methods}

The method is based on remelting a steel 45 alloy electrode in an electroslag furnace under a layer of special slag, into which chemical elements are introduced to remove unwanted impurities from the casting. At the same time, aluminum is added to the steel electrode to remove oxygen from the melt. The castings form a copper mold, which is at the same time a casting mold. To optimize the melting parameters, scientific research works, aluminum was used for melting in various proportions to the amount of the steel electrode. To optimize the modes of conducting melting, a crystallizer with a diameter of $100 \mathrm{~mm}$ to 600 $\mathrm{mm}$ was used in the research.

Let us present the results of analytical studies on the development and analytical implementation of mathematical models of the developed technology for improving the 
operational properties of parts obtained from the alloy steel 45. The method of mathematical modeling is widely used in research. First of all, we will compose a functional dependence for determining the oxygen content depending on the change in the ratio of aluminum in the electrode. Based on the theory of linear algebra, we use the Lagrange interpolation polynomial

$$
P(x), P\left(x_{0}\right)=y_{0}, P\left(x_{1}\right)=y_{1}, \ldots, P\left(x_{n}\right)=y_{n}
$$

For this case, the form of this open system will be as following:

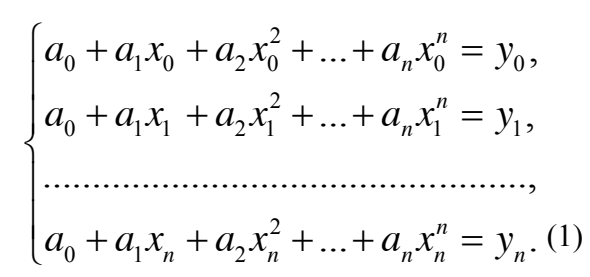

and also, the system of equations $\mathrm{Ax}=\mathrm{Y}$ can be represented in the form of vector

equations:

$$
\left[\begin{array}{ccccc}
1 & x_{0} & x_{0}^{2} & \ldots & x_{0}^{n} \\
1 & x_{1} & x_{1}^{2} & \ldots & x_{1}^{n} \\
\vdots & \vdots & \vdots & \ddots & \vdots \\
1 & x_{n} & x_{n}^{2} & \ldots & x_{n}^{n}
\end{array}\right] \cdot\left[\begin{array}{c}
a_{0} \\
a_{1} \\
\vdots \\
a_{n}
\end{array}\right]=\left[\begin{array}{c}
y_{0} \\
y_{1} \\
\vdots \\
y_{n}
\end{array}\right]
$$

Now, using this system, we will compose functional dependencies to determine the required parameters for various cases.

1) For the case when the diameter of the mold is $400 \mathrm{~mm}$

$$
\begin{aligned}
& n=3, x_{0}=4, x_{1}=8, x_{2}=12, x_{3}=16 \\
& y_{0}=0,035, y_{1}=0,011, y_{2}=0,006, y_{3}=0,002 .
\end{aligned}
$$

According to these values, the algebraic system of equations (1) will take the following form:

$$
\left\{\begin{array}{l}
a_{0}+4 a_{1}+16 a_{2}+64 a_{3}=0,035 \\
a_{0}+8 a_{1}+64 a_{2}+512 a_{3}=0,011 \\
a_{0}+12 a_{1}+144 a_{2}+1728 a_{3}=0,006 \\
a_{0}+16 a_{1}+256 a_{2}+4096 a_{3}=0,002
\end{array} .\right.
$$

Solving the system of equations (3), we find the following coefficients:

$$
a_{0}=0,073824, a_{1}=-0,011673, a_{2}=0,000506, a_{3}=-0,000004
$$

According to this, the form of the functional dependence for determining the number of gases in the melt depending on the aluminum content in the electrode for the diameter of 
the mold will be:

$$
P(x)=0,073824-0,011673 x+0,000506 x^{2}-0,000004 x^{3} .
$$

Here, in Equation (4), $x$ expresses the $\mathrm{A}_{1}$ content in the electrode.

Analysis of the melting results showed that when the amount of $\mathrm{Al}$ is $11.776 \%$, the amount of oxygen in the composition of the melt reaches a minimum value (close to zero). It should be noted that for an ideal condition, functional dependence (4) for the diameter of the mold $(400 \mathrm{~mm})$, the aluminum content in the electrode can accurately predict the amount of oxygen in the resulting melt.

2) For a mold diameter of $300 \mathrm{~mm}$, we have:

$$
\begin{aligned}
& n=3, \lambda_{0}=4, \lambda_{1}=8, \lambda_{2}=12, \lambda_{3}=16 \\
& \mu_{0}=0,035, \mu_{1}=0,021, \mu_{2}=0,013, \mu_{3}=0,011 .
\end{aligned}
$$

For this case, the algebraic system of equations (1) will have the form:

$$
\left\{\begin{array}{l}
a_{0}+4 a_{1}+16 a_{2}+64 a_{3}=0,035 \\
a_{0}+8 a_{1}+64 a_{2}+512 a_{3}=0,021 \\
a_{0}+12 a_{1}+144 a_{2}+1728 a_{3}=0,013 \\
a_{0}+16 a_{1}+256 a_{2}+4096 a_{3}=0,011
\end{array} .\right.
$$

Solving the system of equations (5), we determine the coefficients $a_{0}, a_{1}, a_{2}, a_{3}$ at the values of $a_{0}=0,055, a_{1}=-0,00575, a_{2}=0,000188, a_{3}=0,00002$. This allows you to determine the amount of oxygen in the melt depending on the diameter of the electrode and the amount of aluminum in this electrode:

$$
\mu(\lambda)=0,055-0,00575 \lambda+0,000188 \lambda^{2}-0,000003 \lambda^{3}
$$

If the variable $\lambda$ expresses the aluminum content of the electrode in equation (6) $\mu(\lambda)$ expresses the amount of oxygen in the melt in accordance with the aluminum content of the electrode.

3) For a mold diameter of $200 \mathrm{~mm}$, we have:

$$
\begin{aligned}
& n=4, \lambda_{0}=4, \lambda_{1}=8, \lambda_{2}=12, \lambda_{3}=16 \\
& \mu_{0}=0,035, \mu_{1}=0,025, \mu_{2}=0,019, \mu_{3}=0,013 .
\end{aligned}
$$

The algebraic system of equations for (1) will have the form:

$$
\left\{\begin{array}{l}
a_{0}+4 a_{1}+16 a_{2}+64 a_{3}=0,035 \\
a_{0}+8 a_{1}+64 a_{2}+512 a_{3}=0,025 \\
a_{0}+12 a_{1}+144 a_{2}+1728 a_{3}=0,019 \\
a_{0}+16 a_{1}+256 a_{2}+4096 a_{3}=0,013
\end{array}\right.
$$

Solving the system of equations (7), we determine the values of the coefficients 
$a_{0}, a_{1}, a_{2}, a_{3}$ and find out $a_{0}=0,053, a_{1}=-0,005833, a_{2}=0,000375, a_{3}=-0,00001$. Based on this, the function that determines the amount of oxygen in the melt, depending on the aluminum content in the electrode, will have the form:

$$
\mu(\lambda)=0,053-0,005833 \lambda+0,000375 \lambda^{2}-0,00001 \lambda^{3}
$$

4) For a mold diameter of $100 \mathrm{~mm}$ :

$$
\begin{aligned}
& n=4, \lambda_{0}=4, \lambda_{1}=8, \lambda_{2}=12, \lambda_{3}=16 \\
& \mu_{0}=0,035, \mu_{1}=0,027, \mu_{2}=0,023, \mu_{3}=0,019 .
\end{aligned}
$$

The algebraic system of equations for (1) will have the form:

$$
\left\{\begin{array}{l}
a_{0}+4 a_{1}+16 a_{2}+64 a_{3}=0,035 \\
a_{0}+8 a_{1}+64 a_{2}+512 a_{3}=0,027 \\
a_{0}+12 a_{1}+144 a_{2}+1728 a_{3}=0,023 \\
a_{0}+16 a_{1}+256 a_{2}+4096 a_{3}=0,019
\end{array}\right.
$$

Solving the system of equations (9), we determine the values of the coefficients $a_{0}, a_{1}, a_{2}, a_{3}$ and find out $a_{0}=0,053, a_{1}=-0,005833, a_{2}=0,000375, a_{3}=-0,00001$. Based on this, the function that determines the amount of oxygen in the melt, depending on the aluminum content in the electrode, will have the following form:

$$
\mu(\lambda)=0,053-0,005833 \lambda+0,000375 \lambda^{2}-0,00001 \lambda^{3}
$$

In order to obtain the minimum amount of oxygen in the composition of the melt, let us determine the required amount of $\mathrm{Al}$ in the composition of the electrode, construct the following graph (Fig. 2) of dependences based on the functional dependence (10).

Analysis of the graph shows when the amount of $\mathrm{Al}$ is $21.92 \%$, the amount of oxygen in the composition of the melt reaches a minimum value (close to zero).

Thus, it seems possible to make a functional dependence for determining the oxygen content in the melt depending on the aluminum content in the electrode for any diameter of the mold. To obtain a melt with the required oxygen content in the melt, it is possible to control the aluminum content in the electrode and the diameter of the mold according to expressions (4), (6), (8), (10).

Based on the obtained functional dependencies, it is necessary to emphasize that the development and analytical implementation of a mathematical model makes it possible to simplify practical research. In other words, after conducting preliminary research, you can predict the results of the following experiments.

As in the previous example, the following problem is solved using the Lagrange interpolation polynomial. We write it in the form of the following vector equation: 


$$
\left[\begin{array}{ccccc}
1 & d_{0} & d_{0}^{2} & \ldots & d_{0}^{n} \\
1 & d_{1} & d_{1}^{2} & \ldots & d_{1}^{n} \\
\vdots & \vdots & \vdots & \ddots & \vdots \\
1 & d_{n} & d_{n}^{2} & \ldots & d_{n}^{n}
\end{array}\right] \cdot\left[\begin{array}{c}
a_{0} \\
a_{1} \\
\vdots \\
a_{n}
\end{array}\right]=\left[\begin{array}{c}
H B_{0} \\
H B_{1} \\
\vdots \\
H B_{n}
\end{array}\right]
$$

Where, $\quad n=5, d_{0}=1 \mathcal{M}, d_{1}=1,85 \mu, d_{2}=3,1 \mu, d_{3}=4,4 \mu, d_{4}=5,5 \mu, d_{5}=6 \mu$, $H B_{0}=200, H B_{1}=190, H B_{2}=170, H B_{3}=150, H B_{4}=140, H B_{5}=130[M \Pi a]$, then the system of equations will have the following form:

$$
\left[\begin{array}{ccccc}
1 & 1 & 1 & \ldots & 1 \\
1 & 1.85 & 1.85^{2} & \ldots & 1.85^{5} \\
1 & 3.1 & 3.1^{2} & \ldots & 3.1^{5} \\
1 & 4.4 & 4.4^{2} & \ldots & 4.4^{5} \\
1 & 5.5 & 5.5^{2} & \ldots & 5.5^{5} \\
1 & 6 & 6^{2} & \ldots & 6^{5}
\end{array}\right] \cdot\left[\begin{array}{c}
a_{0} \\
a_{1} \\
a_{2} \\
a_{3} \\
a_{4} \\
a_{5}
\end{array}\right]=\left[\begin{array}{c}
200 \\
190 \\
170 \\
150 \\
140 \\
130
\end{array}\right]
$$

Solving this system of equations, we determine the following results:

$$
\begin{array}{ll}
a_{0}=230,230433, & a_{1}=-58,021149, \quad a_{2}=41,92999, \\
a_{3}=-16,925951, & a_{4}=2,974503, \quad a_{5}=-0,187826
\end{array}
$$

Following this, the surface hardness of the shaft, depending on its diameter after the electroslag furnace, will have the following expression:

$$
H B(d)=230,230433-58,02115 d+41,92999 d^{2}-16,92595 d^{3}+2,974503 d^{4}-0,187826 d^{5} .
$$

Using the functional dependence (13), it is possible to determine the hardness of the shaft surface depending on the shaft diameter.

In the same way, it will be possible to compose functional dependences of the change in the hardness of the surface of the shaft taken from the electric furnace and the change in the hardness of the surface of the shaft taken from the induction furnace concerning the change in the diameter of the shaft.

On the basis of the analytical studies above, it should be noted that with the help of functional dependencies compiled on the basis of graphic data of primary experimental studies, it will be possible to determine the surface hardness of a shaft taken from an electroslag furnace, depending on its diameter. Also, based on the functional dependence (13), it seems possible to determine the hardness without carrying out experimental studies. This, in turn, by facilitating labor-intensive experiments, saving time and energy, will be possible to achieve solid economic efficiency.

\section{Results and Discussion}

Based on the conducted research, we note the following fundamental points. In order to test the developed technology at the central repair and mechanical plant at JSC Almalyk MMC, an analysis of the electrode-aluminum system for melting steel 45 in an electroslag furnace for different shaft diameters was carried out. In order to improve the technology, steelaluminum systems of the following ratio were used: with a mold diameter of 100, 200, 300, 
and $400 \mathrm{~mm}$, aluminum was added to the composition of the 45 steel electrode in an amount of 4, 8, 12 and $16 \%$.

According to the research results, it was revealed that with a mold diameter of 100, 200, and $300 \mathrm{~mm}$, the aluminum content in the electrode is noticeable, and with a diameter of $400 \mathrm{~mm}$, the aluminum content dramatically affected the quality. That is, with an increase in the diameter, the effect of the aluminum content in the steel 45 electrode on the oxygen content sharply increased. Based on this, it can be assumed that with an increase in the diameter, the concentration of the amount of gas in the composition of the casting decreases.

\section{Conclusions}

Based on the research carried out, the following conclusions can be drawn:

1. Developed and implemented a mathematical model of the developed technology for increasing the operational properties of parts obtained from the alloy grade steel 45 .

2. Functional dependencies for determining the number of gases in the melt, depending on the aluminum content in the electrode, a graph of the change in oxygen in the composition of the melt, depending on the increase in the amount of $\mathrm{Al}$ for different diameters of the mold have been made.

3. To obtain a melt with the required oxygen content in it, it is possible to regulate the aluminum content in the electrode and the diameter of the mold; functional dependencies have been drawn up to determine the hardness of the shaft surface depending on the shaft diameter.

Based on the above-mentioned functional dependencies, it should be emphasized that the development and analytical implementation of the mathematical model of the process allow simplifying practical research.

\section{References}

1. Trubilov A.K., Xitryuk V.A. Automotive operating materials, Minsk, (2012)

2. Latash Y.V., Medovar B.I. Electroslag remelting, Moscow, (1970)

3. Zvonarev S.V. Fundamentals of Mathematical Modeling, Yekaterinburg, (2019)

4. Karimov K., Akhmedov A., Kushimov B., Yuldoshev B. Justification, development of a new technology and design for drying seeds of desert fodder plants. IOP Conf. Series: Materials Science and Engineering 883 (2020), 012107, doi:10.1088/1757899X/883/1/012107.

5. Karimov K.A., Akhmedov A. On perspective scientific direction in the theory of mechanisms and machines based on innovative technology. Theoretical and engineering solutions, Technical science and innovation, 3, pp. 199-216, (2020)

6. Grachev V., Turakhodjaev N. Influence of liquid aluminum alloy treatment at temperatures up to $2000{ }^{\circ} \mathrm{C}$ in terms of the alloy structure and gas aluminum oxides content, International Journal of Mechanical Engineering and Technology, 9(7), pp. 489-495, (2018)

7. Nodir Turakhodjaev, Shukhrat, C., Jamaliddin, K., Jaloliddin, E., Kulmukhammad, C. Ways to increase the strength of the surface of the parts, Journal of Critical Reviews, 2020, 7(11), pp. 380-386

8. Wang Y., Zhang S., Wu, R., Liu M., Mardonakulov S. Concurrently improving uniform elongation and strength of ultrafine-grained Al-2Li alloy, Materials Science and Engineering p. 792, (2020) 
9. Turakhodjaev N., Tashbulatov Sh., Zokirov R., Tursunbaev S., Baydullaev A. Studying the scientific and technological bases for the processing of dumping copper and aluminum slags, Journal of Critical Reviews 7(11), ISSN- 2394-5125, (2020) http://dx.doi.org/10.31838/jcr.07.11.79

10. Nodir T., Shukhrat C., Nargiza S., Kulmukhammad, C. Ways to increase the strength of shaftgear teeth working in a highly abrasive grinding environment, Journal of Critical Reviews, 7(7), pp. 904-907, (2020)

11. Wang Y., Zhong F., Wu R., Li X., Zhang M. High-strength, ductility and modulus Al$\mathrm{Li} / \mathrm{B} 4 \mathrm{C}$ composite with near nanostructure produced by accumulative roll bonding, Journal of Alloys and Compounds, 834, 155105 (2020)

12. Nodir, T., Shukhrat, C., Jamaliddin, K., Jaloliddin, E., Kulmukhammad, C. Ways to increase the strength of the surface of the parts//Journal of Critical Reviews, 2020, 7(11), pp. 380-386

13. Dyudkin D.A., Kisilenko V.V. Proizvodstvo stali. Tom 1. Protsessi viplavki, vnepechnoy obrabotki i neprerivnoy razlivki, Smelting, Out-of-Furnace Processing and Continuous Casting Processes, (2008)

14. Voskoboynikov V.G., Kudrin V.A., Yakushev A.M. General metallurgy, 768, pp. 253, (2005)

15. Voskoboynikov V.G., Kudrin V.A., Yakushev A.M. General metallurgy, 768 p. 253, (2002)

16. Krilov S.A., Evgenov A.G., Makarov A.A. Electroslag pressure furnace DESHP-0.1: development and development prospects, (2016)

17. Krilov S.A., Evgenov A.G., Makarov A.A., Tonisheva O.A. Ingot electroslag remelting under pressure, p. 323, (2017)

18. Kazachkov E.A., Chepurnoy A.D., Medovar L.B., Saenko V.Y. Modern electroslag technology in special electrometallurgy, Kiev, (2003)

19. Pyatigin D.A., Chumanov I.V. On the issue of obtaining large forging ingots from high-alloy steels and alloys by the ESR method. Kiev, (2011)

20. Krilov S.A., Makarov A.A., Tonisheva O.A. Reducing the content of non-metallic inclusions in corrosion-resistant nitrogen-containing steel, (2017) 